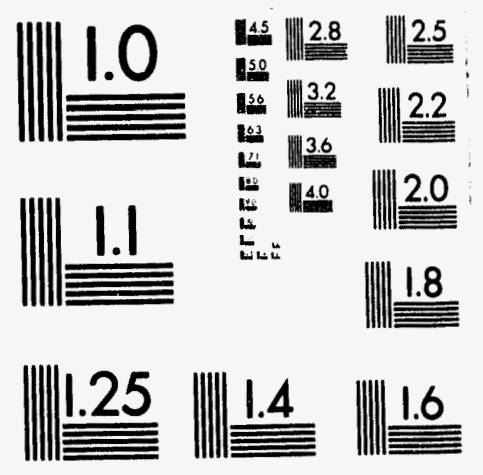



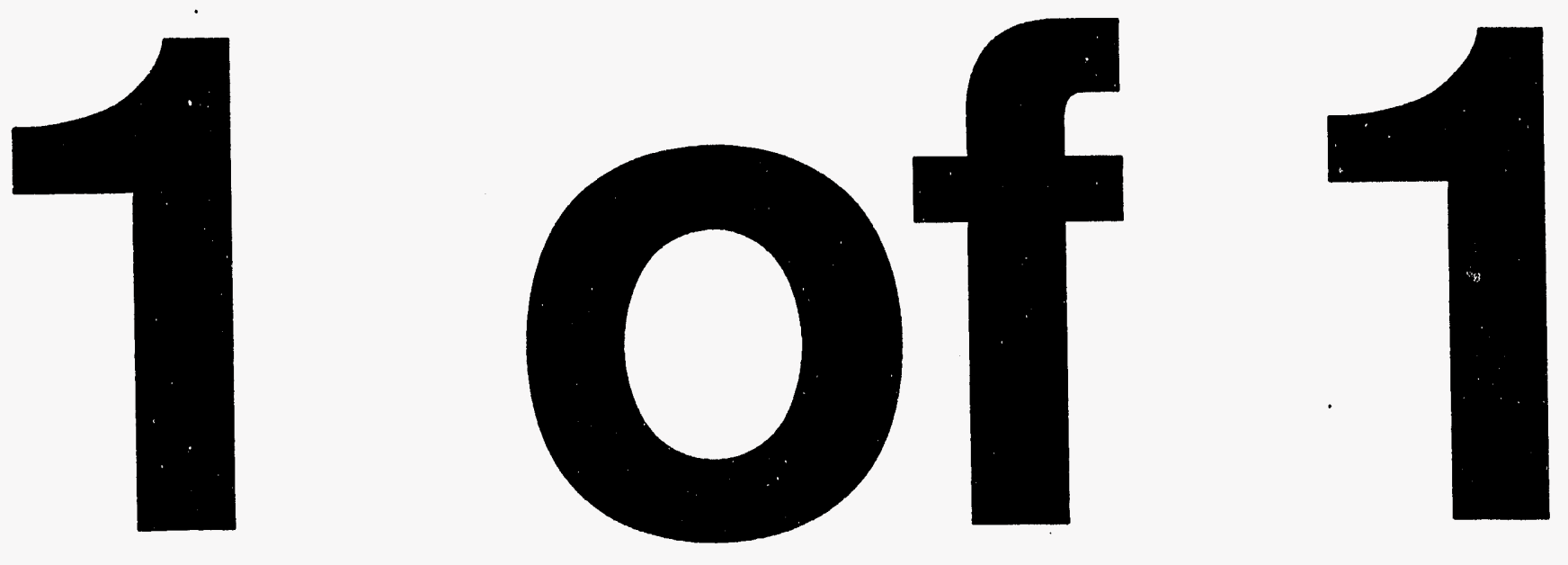


\title{
Implementation of the Wave Propagation Code NPE
}

\author{
Anthony J. C. Ladd \\ John W. White
}

August 20, 1993

This is an informal report intended primarily for internal or limited external distribution. The opinions and conclusions stated are those of the author and may or may not be those of the Laboratory.

Work performed under the auspices of the U.S. Department of Energy by the

Lawrence Livermore National Laboratory under Contract W-7405-Eng-48. 


\section{DISCLAIMER}

This document was prepared as an account of work sponsored by an agency of the United States Government. Neither the United States Government nor the University of California nor any of their employees, makes any warranty, express or implied, or assumes any legal liability or responsibility for the accuracy, completeness, or usefulness of any information, apparatus, produrt, or process disclused, or represents that its use would not infringe privately owned rights. Reference herein to any specific commercial products, process, or service by trade name, trademark, manufacturer, or otherwise, does not necessarily constitute or imply its endorsement, recommendation, or favoring by the United States Government or the University of California. The views and opinions of authors expressed herein do not necessarily state or reflect those of the United States Government or the University of California, and shall not be used for advertising or product endorsement purposes.

This report has been reproduced directly from the best available copy.

Available to DOE and DOE contractors from the Orice of Scientific and Technical Information

P.O. Box 62, ก3k Ridge, TN 37831

Prices available from (615) 576-8401, FTS 626-8401

A vailable to the public from the

National Technical Information Service

US. Department of Commerce

5285 Port Royal Rd.

Springfield, VA 22161 


\title{
Implementation of the wave propagation code NPE
}

\author{
Anthony J.C. Ladd and John W. White \\ Lawrence Livermore National Laboratory \\ Livermore, Ca. 94550
}

August $\quad 20,1993$

\section{Abstract}

The NPE ${ }^{1,2}$ computer program was studied to test its feasibility as a tool in simulating clandestine nuclear tests. The calculational results indicate that the model is accurate. However, computer time is a concern; and validation via experimental data remains to be done.

\section{Motivation}

Lawrence Livermore National Laboratory (LLNL) is investigating the use of hydroacoustic signals to identify clandestine nuclear tests. This project supports non-proliferation activities of the United States Government. A typical scenario of concern involves a nation, like Iraq, conducting a test under heavy cloud cover in a remote location of the ocean such as the southern hemisphere near Antarctica. The proliferant nation would detonate their explosive near the ocean surface, gather data and quickly depart. U.S. interests would be served by timely detection, discrimination and localization of the test. Then investigators could reach the site quickly to identify the testing party. The computer models developed at LLNL for weapon effects studies are well suited for the early portions (strong to weak shocks) of the study. The final part of the study requires the use of an acoustics model. NPE was chosen because it is robust and easy to use. In this paper we describe parameter choices for NPE required to obtain accurate simulations. 


\section{Introduction}

NPE is an acoustic wave propagation code that includes weak nonlinearities in the wave field. The code simulates the evolution of a wave in a frame traveling at the average wave speed. Numerically there were three basic questions to be answered in this preliminary study. 1) How wide does the frame have to be to capture enough of the wave train to give a meaningful result several thousand kilometers from the source? 2) How fine is the zoning necessary to capture all the important details of the wave profile? 3) What are the effects of the nonlinear term: do we need NPE or will a linear propagation code suffice?

\section{Frame size}

The optimum frame size for propagation over large distances is in the range $5-10 \mathrm{~km}$, consistent with the experimental observations of wave trains of about $5 \mathrm{sec}$ duration at $1000 \mathrm{~km}$. In Fig. 1, contour plots of the overdensity $\left(\rho / \rho_{0}-1\right)$ are shown at $80 \mathrm{sec}$ and $90 \mathrm{sec}$ for a frame width of $10 \mathrm{~km}$. It can be seen that successive reflections from the ocean bottom (or surface) gradually catch up with the primary pulse and get absorbed into it. A frame width of several kilometers is required to hold the increasingly complex wave form. Truncation of the frame at $5 \mathrm{~km}$ produces qualitatively similar but quantitatively different results; in Fig. 2, contour plots for a $5 \mathrm{~km}$ frame are compared with the leading $5 \mathrm{~km}$ of a $10 \mathrm{~km}$ frame at at time of $100 \mathrm{sec}$. Frames smaller than $5 \mathrm{~km}$ cannot contain the primary pulse after a few hundred kilometers. Thus a frame width of about $5 \mathrm{sec}$ or $7.5 \mathrm{~km}$ would seem about ideal.

\section{Zoning}

NPE requires fairly fine zoning to produce accurate quantitative results; typically $1 \mathrm{~m}$ zones radially, and $5 \mathrm{~m}$ zones vertically. Sample acoustic traces at short times $(1 \mathrm{sec})$ are shown in Fig. 3, for radial 
zoning of $4 \mathrm{~m}, 2 \mathrm{~m}$ and $1 \mathrm{~m}$. The traces are insensitive to variations in the vertical zone spacing which was $8 \mathrm{~m}$ in all these cases; aspect ratios of 1:5 are about optimum. The truncation of the peak at shallow depths corresponds to a cutoff frequency of about $400 \mathrm{~Hz}$ for $1 \mathrm{~m}$ zones. Thus an accurate calculation would require of the order of $10^{7}$ zones although an order of magnitude less might be sufficient for some purposes. Nevertheless, for long range propagation, one can expect to require $10^{12}-10^{13}$ floating-point operations per run. Improvements to the numerics in the NPE code might substantially reduce the computational cost (by 1 or 2 orders of magnitude), but it is clear that parallel computing will be necessary for prompt results.

\section{Non-linear effects}

The test problem involved a spherical outgoing shockwave of radius $280 \mathrm{~m}$ and peak pressure of just over $1 \mathrm{kbar}$. For this problem nonlinear effects are noticeable but small, and probably negligible; in Fig. 4 the linear solution is shown on the left, the non-linear solution is on the right. About a 10 times stronger shock would be needed for significant nonlinearity.

\section{S u m m a r y}

The NPE code is clearly capable of modeling the propagation of acoustic waves accurately for long distances. Our main concern is whether the cost will be prohibitive. We will need to determine the accuracy needed for discrimination purposes with respect to seismic signals. High precision may not be needed. We anticipate getting data from a hydroacoustic array soon, and this is expected to resolve the issue; plus we will have an opportunity to validate the entire simulation process. Most calculations (parameter variations etc.) needed in the near term do not require fine zoning, so that cost concerns can be deferred. 

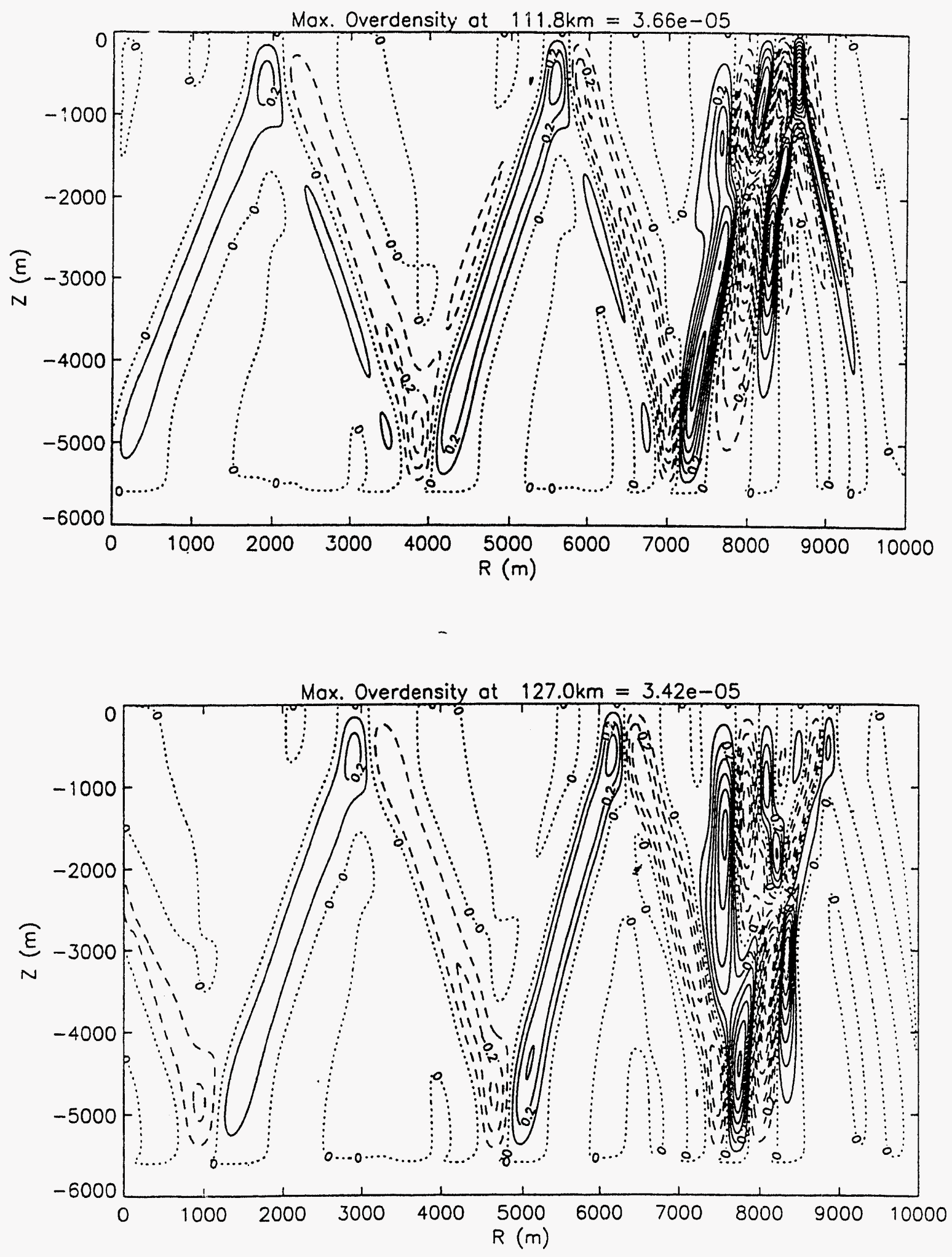

Figure 1. Overdensity $\left(\rho / \rho_{o}-1\right)$ plots for a frame width of $10 \mathrm{~km}$. The upper one is at $80 \mathrm{sec}$; the lower at $90 \mathrm{sec}$. 

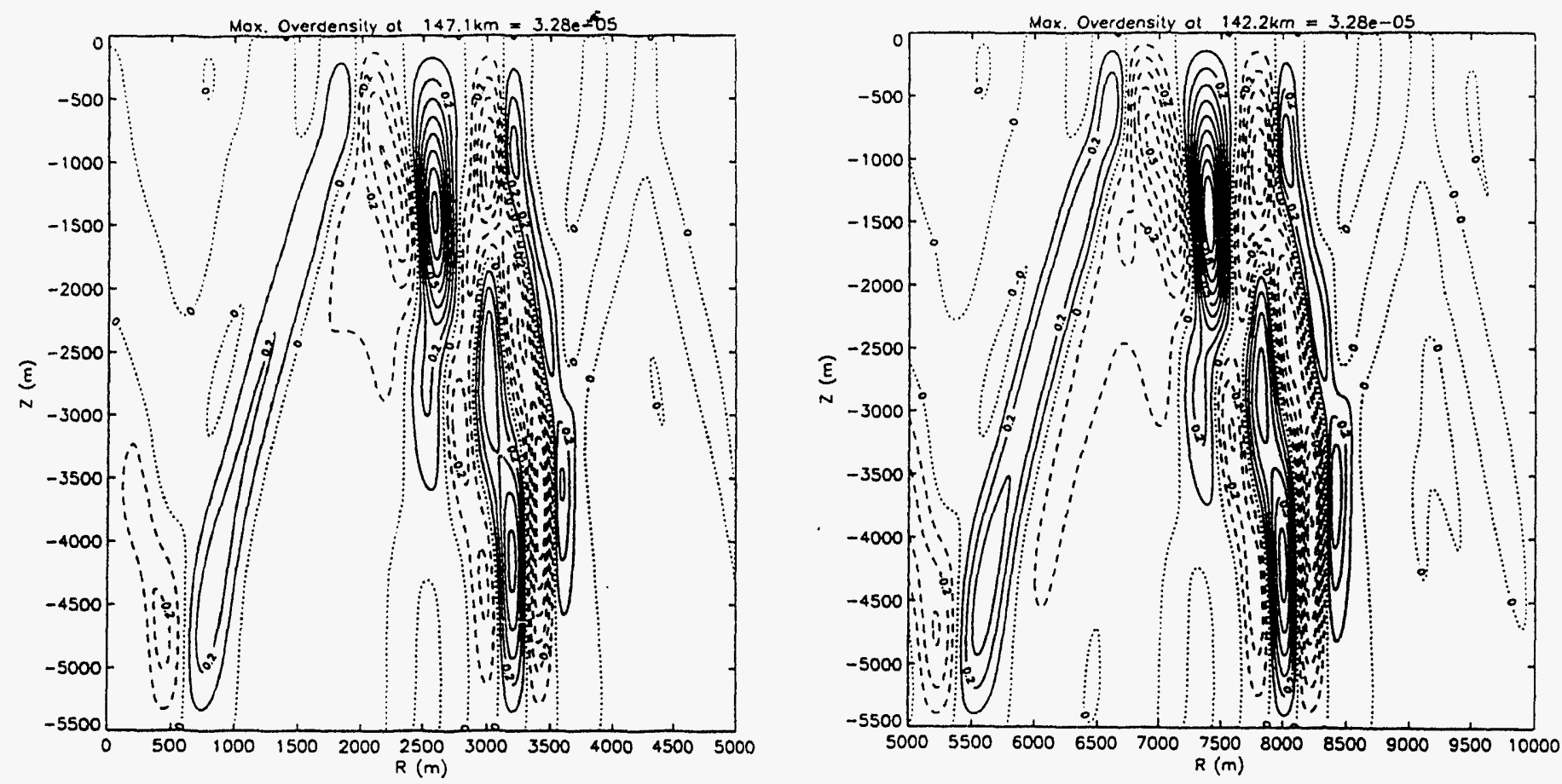

Figure 2. Overdensity $\left(\rho / \rho_{0}-1\right)$ plots at $100 \mathrm{sec}$. The left figure from a run using a $5 \mathrm{~km}$ window and the right figure from a run using a $10 \mathrm{~km}$ window, but with only the first $5 \mathrm{~km}$ plotted (for easy comparison). The two figures are quite similar, but the right one retains considerably more detail. 

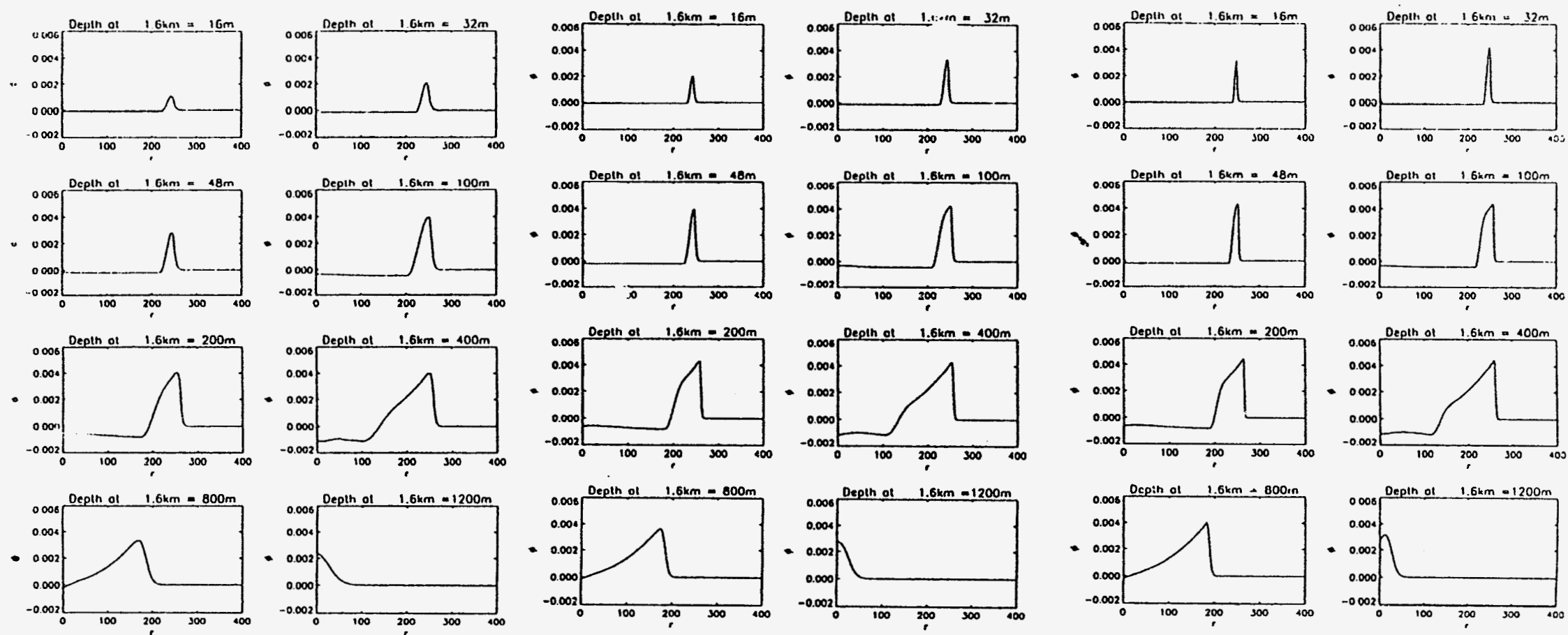

Figure 3. The two left columns of plots are from a calculation using horizontal zones of $4 \mathrm{~m}$ width, and they show the shape of the (continuously renormalized) acoustic signal as it propagates from $16 \mathrm{~m}$ to $1200 \mathrm{~m}$ (all at a depth of $1.6 \mathrm{~km}$ ). The next two columns repeat the pattern for zones whose horizontal width is $2 \mathrm{~m}$. The last two columns repeat the pattern for $1 \mathrm{~m}$ wide zones. The sharper signals with fine horizontal zoning are clearly displayed; but there was no such sensitivity to zone fineness in the vertical direction. 


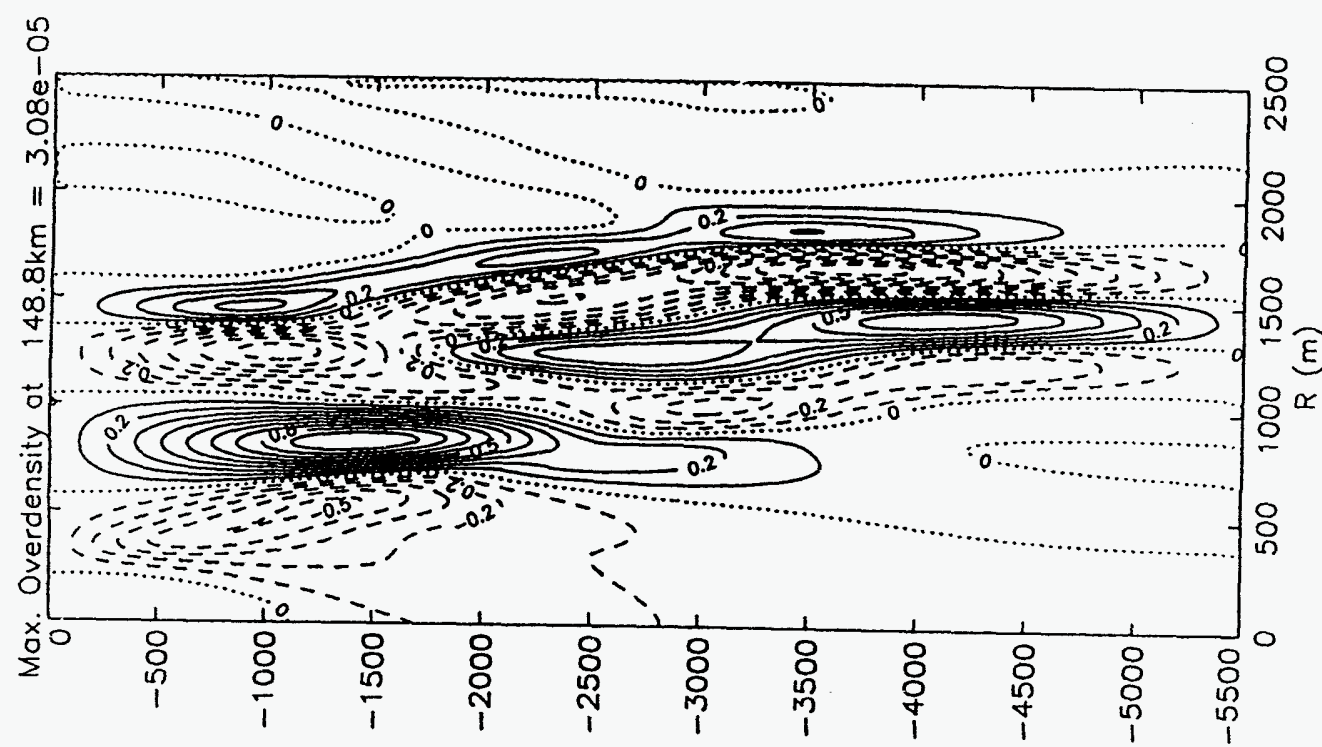

(w) $z$

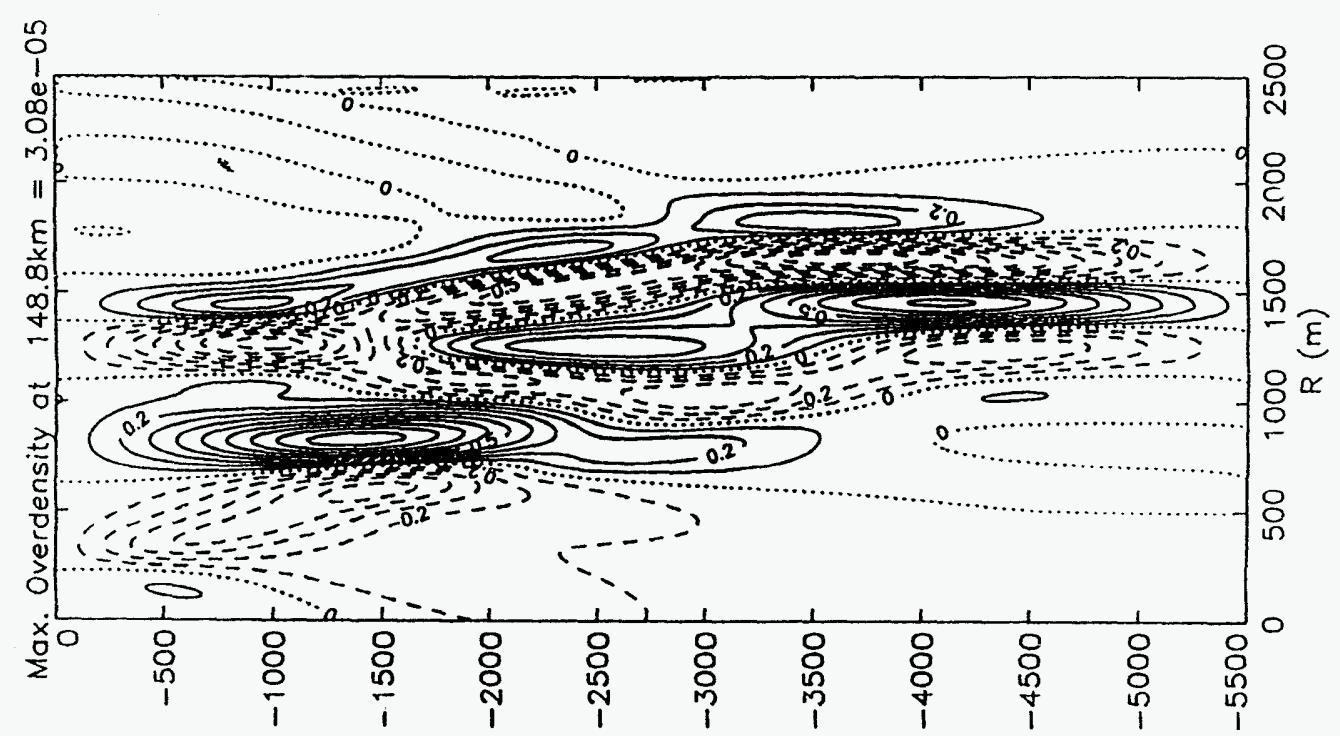

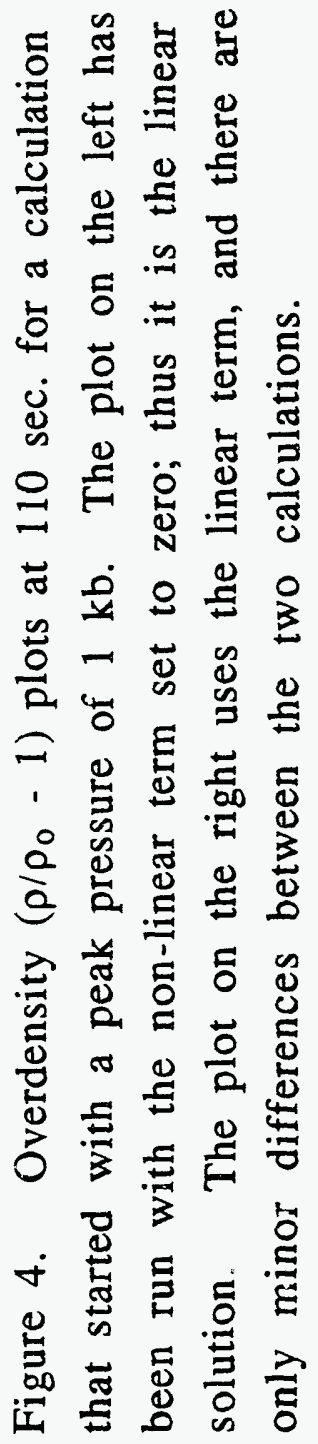

(u) $\mathrm{Z}$ 


\section{References}

1 McDonald, B. E. and Kuperman, W. A., "Time-Domain Solution of the Parabolic Equation Including Non-linearity," Comp. and Maths. with Appls. vol 11, pp843-851, Pergamon Press Ltd. 1985, Great Britain

2 Ambrosiano, J. J., Plante, D. R., McDonald, B. E. and Kuperman, W. A., "Nonlinear Propagation in an Ocean Acoustic Waveguide," J. Acoust Soc. Am. vol 87 (4), pp1473-1482, 1990 

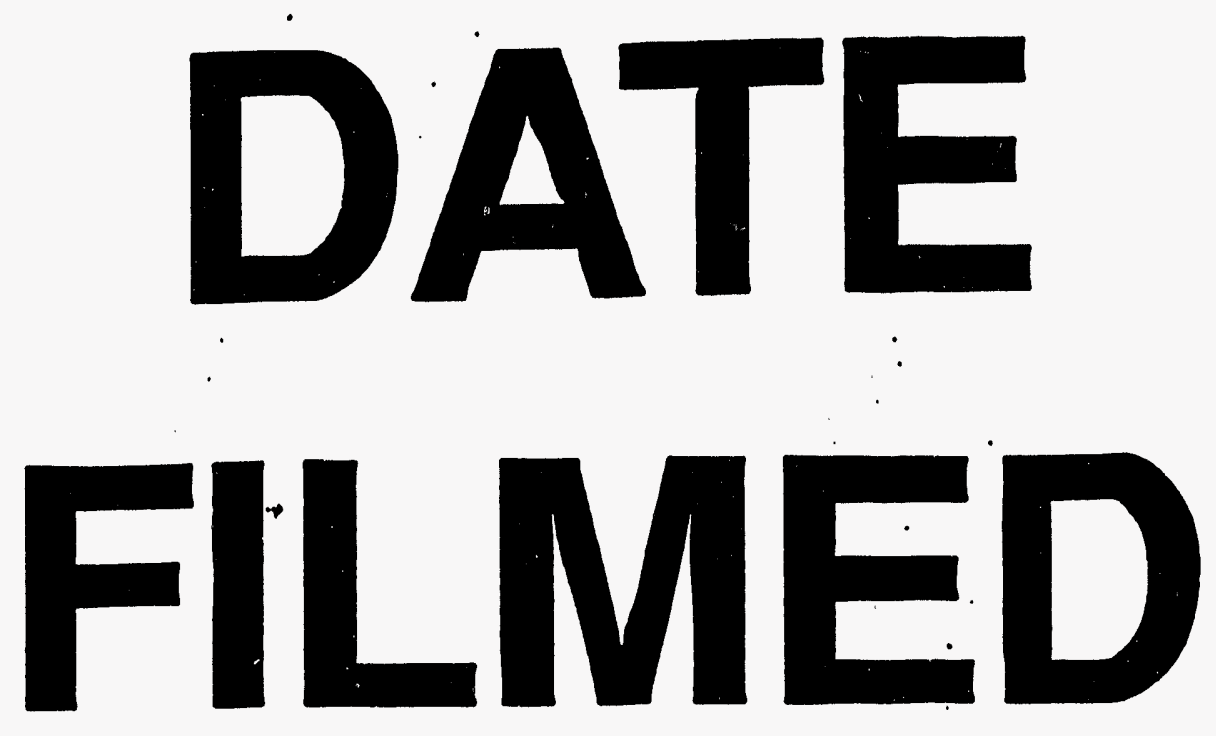

$2 / 22 / 94$
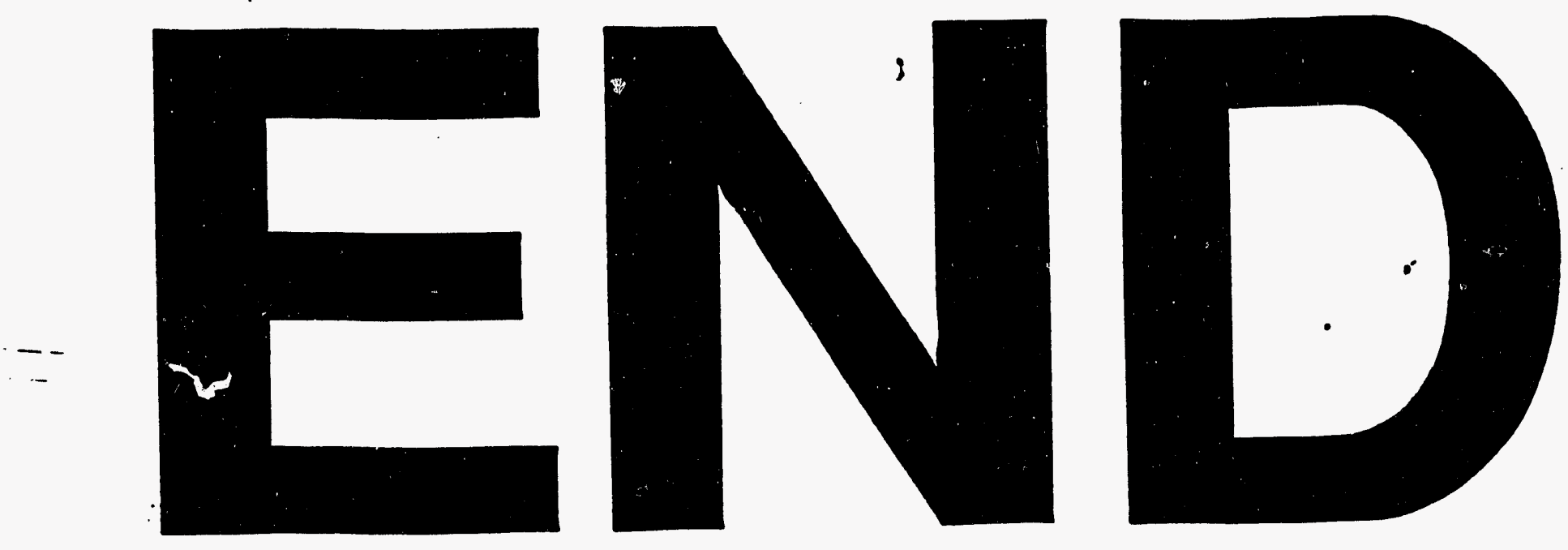